\title{
A experimentação investigativa no ensino de química: construindo uma torre de líquidos
}

Matheus Junior Baldaquim matheusbaldaquim@gmail.com orcid.org/0000-0001-7816-8709 Universidade Estadual de Maringá (UEM), Maringá, Paraná, Brasil

\section{Amanda Oliveira Proença} amanda.proenca@hotmail.com orcid.org/0000-0003-3263-7113 Londrina, Paraná, Brasil

Mateus Carneiro Guimarães dos Santos

carneiraum2@gmail.com Orcid.org/0000-0002-5859-0248 Maringá, Paraná, Brasil

\section{Marcia Camilo Figueiredo} marciacamilof@gmail.com orcid.org/0000-0001-5651-5984 Universidade Tecnológica Federal do Paraná (UTFPR), Londrina, Paraná, Brasil

Marcelo Pimentel da Silveira mpsilveira@uem.br orcid.org/0000-0003-3224-116X Universidade Estadual de Maringá (UEM) Maringá, Paraná, Brasil

\section{RESUMO}

É extensa a literatura que aponta as razões das dificuldades de assimilação dos conceitos por parte dos alunos. A apresentação dos conceitos muitas vezes os torna abstratos e desvinculados da realidade, o que pode causar desinteresse em aprender. Assim, essa pesquisa tem por objetivo a aplicação de estratégias capazes de superar esse desinteresse, estimulando os alunos a se envolverem com a atividade, criando hipóteses e questionamentos sobre os fenômenos estudados. Para isso, utilizamos a prática investigativa. A atividade foi realizada em uma turma de primeiro ano do Ensino Médio com base na metodologia proposta por Delizoicov, Angotti e Pernambuco (2002), os três momentos pedagógicos, denominados problematização inicial, organização do conhecimento e aplicação do conhecimento. A partir disso, pode-se verificar as dificuldades dos alunos no primeiro momento e estimulá-los a evoluir no segundo e terceiro momento, comprovando a importância dessa abordagem no Ensino de Química. Faz-se importante enfatizar que o professor deve ser incentivado e preparado para que as ações sejam efetivas no processo de ensino e aprendizagem.

PALAVRAS-CHAVE: Ensino de Química. Atividade Experimental. Abordagem Investigativa. 


\section{INTRODUÇÃO}

Na área do Ensino de Ciências é comum encontrarmos inúmeras metodologias auxiliares no processo de ensino e aprendizagem, nas quais muitas vezes são utilizadas no planejamento de atividades desenvolvidas pelos professores que não se sentem satisfeitos com a pedagogia tradicional que, segundo Paulo Freire se caracteriza como educação bancária, ou seja, o professor se torna mero transmissor das informações, havendo repetição e aplicação de respostas prontas, assim o aluno apenas recebe e contabiliza as informações.

O modelo tradicional de ensino pode gerar nos alunos um grande desinteresse em aprender. Também é importante destacar a complexidade de abstração para compreender os conceitos químicos, de modo que, negar essa dificuldade pode ser considerado ingenuidade.

Nunes e Adorni (2010) confirmam essa concepção de que no Ensino de Química é frequente que os alunos não consigam aprender associando o conteúdo com o dia a dia, dessa forma, eles se desinteressam pelo tema, indicando que o ensino está sendo realizado de maneira errônea.

Pela facilidade do acesso ao conhecimento de forma rápida, podem ser encontrados diferentes recursos didáticos e instrumentos que auxiliam o professor de Química com alternativas para melhorar suas aulas ditas como tradicionais, tais como: recursos tecnológicos, jogos didáticos, a experimentação, entre outros.

Algumas formas de tentar minimizar tais dificuldades encontradas pelos docentes podem ser: trabalhar o conteúdo químico ou utilizar materiais que estejam próximos ao dia a dia do aluno, incentivar a reflexão durante as aulas, considerar os conhecimentos que cada aluno traz consigo sobre determinados conceitos, trabalhar em suas aulas de forma sistematizada e clara, apresentando os objetivos de cada aula e instigando a curiosidade e atenção dos alunos (SANTOS; SCHNETZLER, 1996).

Uma das alternativas encontradas para trabalhar a Química de forma contextualizada são as atividades investigativas por meio de abordagens experimentais, despertando nos alunos interesses que os levem a compreender de forma adequada os temas trabalhados em sala de aula (GIORDAN, 1999).

Oliveira e Soares (2010) reforçam que a experimentação apresenta várias contribuições, tais como: motiva e desperta a atenção dos alunos, desenvolve trabalhos em grupos e incentiva a tomada de decisões, estimula a criatividade, aprimora as capacidades de observação, registro, análise de dados e proposições de hipóteses para os fenômenos, aprendem conceitos científicos, detectam e corrigem erros conceituais dos alunos, compreendem a natureza das Ciências, as relações entre Ciência, Tecnologia e Sociedade e aprimora habilidades manipulativas.

Apesar da importância da experimentação como ferramenta facilitadora no Ensino de Química, ainda assim, a maioria dos professores não a utiliza como ferramenta pedagógica (MALDANER, 2003). A justificativa para isso recai muitas vezes na estrutura inadequada dos colégios, ou seja, a falta de reagentes, espaços que não fornecem a segurança necessária e inviabilizam as atividades práticas, carência de profissionais responsáveis pelo laboratório, entre outros. 
Diante desta problemática, foi proposta a realização de uma atividade experimental investigativa - A Torre de Líquidos - em uma turma de 10 ano de uma escola pública da cidade de Londrina/PR a fim de desenvolver nos alunos a curiosidade, envolvendo elementos que fossem próximos a sua realidade, para assim, instigar hipóteses e questionamentos. Buscou-se auxílio na metodologia dos três momentos pedagógicos proposta por Delizoicov, Angotti e Pernambuco (2002).

\section{ATIVIDADE EXPERIMENTAL INVESTIGATIVA}

A partir de 1986 as atividades experimentais para fins didáticos passam a ganhar destaque, sendo a Universidade de Harvard uma das pioneiras, publicando uma lista de 40 experimentos para aulas de Física (WILSEK, 2009). Por meio de situações simples, o professor deve instituir um problema inicial, discutir as opiniões formuladas pelos alunos e provocar dúvidas que despertem a curiosidade dos aprendizes, permitindo-lhes fazer inferências que solucionem o problema (OLIVEIRA; SOARES, 2010).

A experimentação investigativa é frequentemente a mais defendida por diversos autores: Gil-Pérez e Valdez Castro (1996), Araújo e Abib (2003), Wilsek (2009), Oliveira e Soares (2010). Estes consideram a prática como uma forma de permitir aos alunos maior poder de decisão sobre as atividades desenvolvidas, contribuindo para uma melhor aprendizagem do conteúdo.

No Ensino por investigação os alunos são colocados em situação de realizar pequenas pesquisas, combinando simultaneamente conteúdos conceituais, procedimentais e atitudinais. Zômpero e Laburú (2011) analisam os pressupostos do ensino por investigação com base em estudos de diferentes abordagens e autores, ressaltando que as atividades devem partir sempre de situações problemas. Essas situações podem ser levantadas tanto pelos alunos como pelos professores, sendo de fundamental importância que "os alunos se interessem pelo problema a ser investigado, de forma a serem motivados a resolvê-lo" (ZÔMPERO; LABURÚ, 2011, p. 75).

Suart e Marcondes (2008) deixam claro que o procedimento experimental do tipo receita de bolo sem a discussão e análise dos resultados tem baixo poder cognitivo perante o objetivo maior do ensino de ciências, pois apenas reforçam a prática da memorização e repetição. Apontam ainda a capacidade da atividade experimental investigativa de desenvolver habilidades de alto poder cognitivo.

Em seu livro Metodologia do Ensino de Ciências, Delizoicov e Angotti (2000) mostram que:

[...] Não é suficiente 'usar o laboratório' ou 'fazer experiências', podendo mesmo essa prática vir a reforçar o caráter autoritário e dogmático do ensino de ciências e, também, descaracterizar o empreendimento da ciência. Atividades experimentais planejadas e efetivadas somente para 'provar' aos alunos leis e teorias são pobres relativamente aos objetivos de formação e apreensão de conhecimentos básicos em ciências. (DELIZOICOV; ANGOTTI, 2000, p. 22).

Diante dessa problemática referente ao modo como os experimentos são abordados em sala de aula, é bastante evidente a necessidade de mudança na 
forma como se elaboram atividades experimentais nas aulas de ciências, principalmente de química.

Araújo e Abib (2003) argumentam que a experimentação investigativa fornece aos alunos o desenvolvimento das capacidades de trabalho em grupo, observação, discussão e outras características importantes no desenvolvimento da aprendizagem. Ademais, leva-se em consideração a busca pela resposta e explicação dos fenômenos que são desafiadores e prendem a atenção dos alunos, portanto os resultados não são previsíveis.

Delizoicov e Angotti (2000) reconhecem que:

Considera-se mais conveniente um trabalho experimental que dê margem à discussão e interpretação de resultados obtidos (quaisquer que tenham sido), com o professor atuando no sentido de apresentar e desenvolver conceitos, leis e teorias envolvidas na experimentação. Desta forma o professor será um orientador crítico da aprendizagem, distanciando-se de uma postura autoritária e dogmática no ensino e possibilitando que os alunos venham a ter uma visão mais adequada do trabalho em ciências. (DELIZOICOV; ANGOTTI, 2000, p. 22).

Outra vantagem da aprendizagem pela investigação é a percepção dos alunos sobre como ocorre o processo de construção dos conhecimentos, no qual caracteriza o método científico como a realização de experimentações, observações, coletas de dados, análises e divulgação de resultados na comunidade científica (HODSON, 1994 apud OLIVEIRA; SOARES, 2010).

\section{EXPERIMENTAÇÃO INVESTIGATIVA NO ENSINO DE QUÍMICA}

Desde a Idade Média, Aristóteles (1979) já defendia a experimentação como fonte de conhecimento afirmando que, "quem possua a noção sem a experiência, e conheça o universal ignorando o particular nele contido, enganar-se-á muitas vezes no tratamento" (apud GIORDAN, 1999, p. 43). Houve muitas transformações no pensamento científico até chegar às ideias positivistas, que influenciam as práticas pedagógicas na área de ensino se Ciências nas escolas, principalmente no ensino de Química. Portanto:

Saber lecionar e hierarquizar variáveis, segundo critérios de pertinência para a compreensão dos fenômenos, controlar e prever seus efeitos sobre os eventos experimentais, encadear logicamente sequências de dados extraídos de experimentos, são consideradas, na visão positivista, competências de extremo valor para a educação científica do aluno. (GIORDAN, 1999, p. 45).

Além de a experimentação ser utilizada como um instrumento que auxilia no desenvolvimento de competências ditas por Giordan (1999), também exerce um papel de legitimador do conhecimento científico. Até o final dos anos 60 predominou nas aulas de Química explicar o método científico e aplicá-lo, este era o objetivo para se realizar uma boa experimentação em sala de aula.

Segundo Schnetzler e Aragão (1995), a partir dos anos 60 a cultura de pesquisa começou a ser fortemente desenvolvida pelos programas de educação científica, os estudos levaram em conta a evolução do pensamento e as ideias prévias dos alunos e não apenas a execução de um passo a passo do método científico. 
Suart e Marcondes (2008) afirmam ainda que:

\begin{abstract}
As atividades orientadas para o desenvolvimento cognitivo do aluno, podem permitir que estes construam suas explicações para a compreensão do fenômeno, estabelecendo relações entre os dados e fatos químicos observados. Pode-se oferecer ao aluno a oportunidade de pensar sobre o problema, resolvê-lo através da experimentação, relatar e discutir suas ideias, que poderão contribuir para o processo de conceituação do fenômeno químico (SUART; MARCONDES, 2008, p. 04).
\end{abstract}

Nas escolas ainda se busca incluir a experimentação no currículo, mas vários pesquisadores apesar de ver a experimentação como uma metodologia que de fato auxilia na construção do pensamento crítico reflexivo, mas, não concordam com o modo como as experiências têm sido realizadas (HODSON, 1994; GIL-PERÉZ; VALDÉS CASTRO, 1996; GONZALES, 1992; WATSON et al., 1995).

Gabel et al. (1984), critica a experimentação como um procedimento seguido em forma de uma receita, em que os alunos apenas respondem os problemas de laboratório utilizando estratégias algorítmicas e não conseguem compreender os conceitos químicos desenvolvidos na sala de aula.

Segundo as Diretrizes Curriculares do Paraná:

[...] é necessário perceber que o experimento faz parte do contexto de sala de aula e que não se separa a teoria da prática. Isso porque faz parte do processo pedagógico que os alunos se relacionem com os fenômenos sobre os quais se referem os conceitos a serem formados e significados. (PARANÁ, 2006, p. 20).

Destaca-se ainda que o aluno deve ser sujeito ativo na construção do conhecimento. A atividade experimental é um método didático que proporciona ao aprendiz ter uma atitude ativa, aprendendo melhor pela experiência direta (HODSON, 1988). No Quadro 1, estão apresentados alguns dos métodos didáticos utilizados para se realizar a atividade experimental em sala de aula.

Quadro 1 - Tipos de atividades de Experimentação

\begin{tabular}{c|c} 
Atividade experimental & Descrição \\
\hline Demonstrativa & $\begin{array}{r}\text { O professor é o experimentador, sujeito principal. Cabe ao } \\
\text { aluno a atenção e o conhecimento do material utilizado. } \\
\text { O aluno observa, anota e classifica. }\end{array}$ \\
\hline Ilustrativa & $\begin{array}{r}\text { É realizada pelo aluno que manipula todo o material sob a } \\
\text { direção do professor. }\end{array}$ \\
\hline Descritiva & $\begin{array}{r}\text { É realizada pelo aluno sob a observação ou não do } \\
\text { professor. O aluno entra em contato com o fenômeno. }\end{array}$ \\
\hline Investigativa & $\begin{array}{c}\text { É realizada pelo aluno, que discute ideias, elabora hipóteses } \\
\text { e usa da experimentação para compreender os fenômenos } \\
\text { que ocorrem. A participação do professor é dada na } \\
\text { mediação do conhecimento. }\end{array}$ \\
\hline
\end{tabular}

Fonte: Oliveira e Soares (2010).

São encontrados nos periódicos, como a Química Nova na Escola, diversos 
importância da execução de experimentos em sala de aula que não sejam apenas demonstrativos, mas que gerem reflexão do aluno resultando em hipóteses até a compreensão dos fenômenos.

Dessa forma, a atividade escolhida para o desenvolvimento desse trabalho foi a utilização do experimento Torre de Líquidos como uma estratégia para trabalhar conceitos de densidade e misturas homogêneas e heterogêneas. Para isso, foi utilizada a experimentação Investigativa, na qual os alunos tornam-se participantes ativos, discutindo e elaborando diferentes hipóteses que podem ser corroboradas ou falseadas por meio da situação problemática.

\section{TRÊS MOMENTOS PEDAGÓGICOS NO ENSINO DE QUÍMICA}

De acordo com Delizoicov, Angotti e Pernambuco (2002), o primeiro momento pedagógico deve ser composto de levantamento de questões que tenham como objetivo relacionar situações do cotidiano para estimular os alunos a participarem de discussões sobre o conteúdo a ser trabalhado.

Para isso, antes de iniciar a problematização do tema, o professor pode utilizar um questionário inicial para verificar as ideias que os alunos possuem, porque "[...] pode ser que o aluno já tenha noções sobre as questões colocadas, fruto da sua aprendizagem anterior, na escola ou fora dela. Suas noções poderão estar ou não de acordo com as teorias e as explicações das ciências [...]" (DELIZOICOV; ANGOTTI; PERNAMBUCO, 2002, p. 201). Além disso,

[...] a problematização poderá permitir que o aluno sinta necessidade de adquirir outros conhecimentos que ainda não detém; ou seja, coloca-se para ele um problema para ser resolvido. Eis por que as questões e situações devem ser problematizadas (DELIZOICOV; ANGOTTI; PERNAMBUCO, 2002, p. 201).

O segundo momento pedagógico requer uma orientação do professor durante o desenvolvimento dos conceitos propostos a fim de que o aluno comece a enxergar as diversas possibilidades de interpretação e explicação dos fenômenos ocorridos, passando a melhor interpretarem as situações do seu cotidiano. Portanto, é o momento de se estudar o "[...] conteúdo programático com o qual a 'estrutura profunda' da codificação pode ser apreendida. É o momento de análise dos fatos procurando superar a visão sincrética e eminentemente descritiva, até então exposta" (DELIZOICOV, 1982, p. 150 apud MARENGÃO, 2012, p. 30).

O papel do professor é muito importante nesse momento, porque os seus
questionamentos vão ocorrendo por meio de "[...] observações sistemáticas
do meio e/ou em experimentos relacionados diretamente com os fenômenos
e é dirigido para a compreensão do processo de transformação envolvido (a
'estrutura profunda' da codificação)" (DELIZOICOV, 1982, p. 150 apud
MARENGÃO, 2012, p. 30). Então, durante a problematização em torno das
'codificações auxiliares' (as observações de fatos e/ou os experimentos), o
professor irá definindo, conceituando, enfim obtendo e fornecendo as
informações que delas possam ser abstraídas (DELIZOICOV, 1982, p. 150 apud
MARENGÃO, 2012, p. 30).

No terceiro momento pedagógico, o professor deve trabalhar sistematicamente o conteúdo desenvolvido a fim de aprimorar o conhecimento 
que foi estimulado no aluno durante a execução da proposta, interpretando as situações estudadas e outras que possam ocorrer no cotidiano do aluno de forma mais científica e correta possível.

Na 'Aplicação do Conhecimento' podemos também ampliar o quadro das informações adquiridas ou ainda abranger conteúdo distinto da situação original (abstraídas do cotidiano do aluno), mas decorrente da própria aplicação do conhecimento. É particularmente importante considerar esta função da 'aplicação do conhecimento'; é ela que, ampliando o conteúdo programático, extrapola-o para uma esfera que transcende o cotidiano do aluno. (DELIZOICOV, 1982, p.150 apud MARENGÃO, 2012, p. 30).

Portanto, é no momento da aplicação do conhecimento que o aluno se torna capaz de compreender cientificamente o fenômeno estudado. Dessa forma, o professor deve atuar com cautela para que o objeto de estudo do cotidiano seja assimilado corretamente e transformado em conhecimento científico.

\section{METODOLOGIA}

Considerando o panorama e as dificuldades encontradas nas escolas públicas, uma das atividades propostas na disciplina de Estágio Supervisionado III, realizado no 70 período do Curso de Licenciatura em Química da Universidade Tecnológica Federal do Paraná foi a elaboração e aplicação de um projeto de ensino, que teve o intuito de aprimorar as práticas docentes e contribuir no desenvolvimento de atividades criativas que auxiliem na capacidade do aluno estagiário em planejar propostas metodológicas para o ensino de química.

A atividade foi realizada em um Colégio da rede Estadual de Ensino do Paraná,

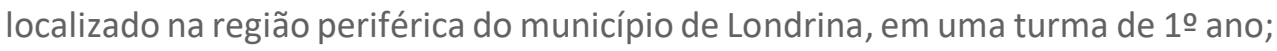
ressalta-se que essa foi a primeira experiência dos alunos com atividades práticas no Ensino de Química devido a infraestrutura precária da escola.

Foi proposta uma atividade experimental investigativa dividida em três partes, primeiro, aplicação de um questionário inicial; em seguida o desenvolvimento da atividade experimental denominada: Torre de Líquidos, fundamentada nos três momentos pedagógicos por Delizoicov, Angotti e Pernambuco (2002); por fim, a aplicação do questionário final.

Para o questionário inicial e final foram elaboradas 4 questões, a primeira foi para verificar as concepções que os alunos detinham sobre a definição de mistura homogênea; a questão 2 tratou de conceitos de mistura heterogênea; a terceira e quarta questão do tipo aberta, entendida aqui como aquela que permite ao entrevistado responder com suas próprias palavras, sem correr o risco de ser influenciado pelas alternativas apresentadas, assim, questionou-se os conhecimentos que os alunos têm sobre densidade e a relação entre densidade e mistura, respectivamente. 0 questionário foi aplicado para 30 alunos, no início e após a atividade, utilizado para análise dos conceitos prévios e da evolução dos alunos, esse levantamento permite que o professor estabeleça "relações com o conteúdo sobre o qual se concentrará o processo de ensino, o que valoriza a aprendizagem e fundamenta a construção dos novos significados" (BARATIERI et al., 2008, p. 21). 


\section{PRIMEIRO MOMENTO}

Inicialmente, os 30 alunos foram divididos em 5 grupos e desafiados a montar uma torre de líquidos como na Figura 1; cada grupo recebeu as informações contidas no Quadro 2 e ficaram responsáveis por formular uma única hipótese, colocando de acordo com os valores de densidade a ordem correta dos líquidos para formar a torre representada na imagem.

Quadro 2 - Informações cedidas aos alunos

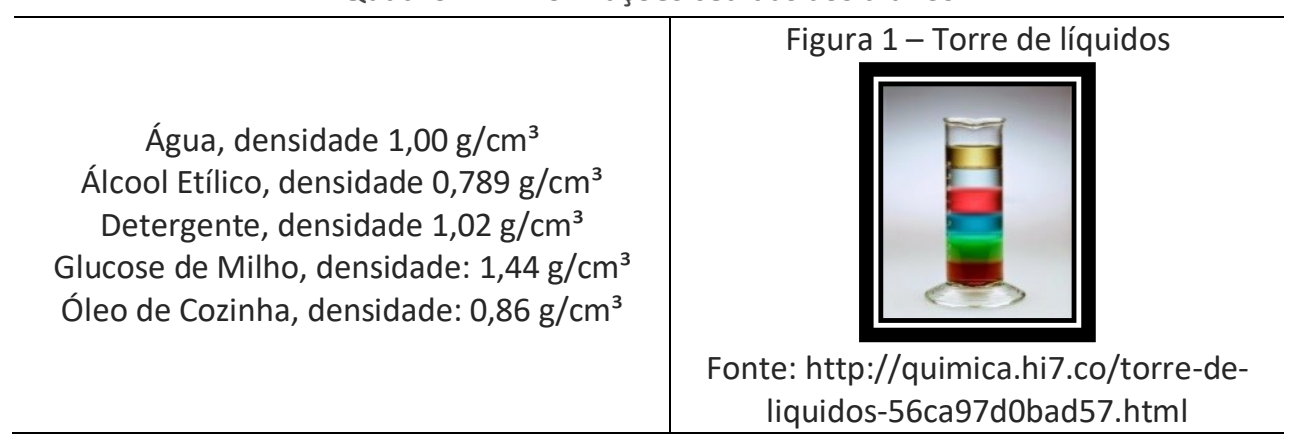

Fonte: Autoria própria (2017).

Nesse momento de formulação das hipóteses, os alunos foram indagados em grupo com diversas perguntas no intuito de estimular a participação e curiosidade, contextualizando as aulas com momentos relacionados ao cotidiano.

O questionário inicial auxiliou nesta etapa para que o aluno mostrasse interesse pelo tema na busca das respostas ao problema estabelecido. Segue algumas questões feitas:

\footnotetext{
Qual a maneira mais adequada para fazer a torre sem que os líquidos se misturem homogeneamente?

O que acontece com a água e o óleo quando colocados em um recipiente?
}

Vale ressaltar que as questões realizadas são norteadoras da proposta, sendo assim, houve a observação da imagem torre de líquidos e o desafio de montá-la de acordo com as informações fornecidas pelo professor, ou seja, a densidade dos líquidos disponibilizados.

\section{SEGUNDO MOMENTO}

A organização do conhecimento ocorreu durante o próprio experimento. Cada grupo ficou responsável por executar sua hipótese, um de cada vez, sendo que o restante da turma observava o ocorrido e ajudava com explicações.

Em cada grupo surgiu uma necessidade conceitual diferente, tais como: pastoso, estabilidade, peso e densidade e solubilidade. Então, coube ao professor orientar os alunos a auxiliá-los no processo de construção do conhecimento na prática pedagógica, relacionando a ordem estabelecida por eles de acordo com o que a teoria aborda, sem dar as respostas prontas e acabadas. 


\section{TERCEIRO MOMENTO}

Após as indagações e dúvidas dos alunos, o professor os levou para a sala de aula para explanação dos conceitos científicos. Dessa forma, os alunos puderam ver a relação entre a atividade prática investigativa e a sua aplicação teórica.

Neste momento, o professor já havia analisado as respostas do questionário inicial, logo, a sistematização do conteúdo e a condução das perguntas e hipóteses durante o terceiro momento foi facilitado. O professor conseguiu conduzir sua aula de acordo com o observado durante os 2 primeiros momentos pedagógicos e com o questionário inicial dos alunos. Por fim, foi aplicado novamente o questionário com as mesmas perguntas iniciais, para verificar se houve mudança na concepção dos alunos sobre os conceitos trabalhados.

\section{ANÁLISE E DISCUSSÃO DOS DADOS}

Essa pesquisa é de caráter qualitativo buscando uma compreensão abrangente e subjetiva com base na interpretação de registros produzidos (LÜDKE; ANDRÉ, 1986).

A interpretação e discussão das respostas dadas aos questionários foram feitas com base na análise de conteúdo de Bardin (2007); existem etapas para uma boa análise de conteúdo que se organizam em: pré-análise, exploração do material e tratamento dos resultados.

Com as respostas do questionário inicial em mãos, os dados foram sistematizados de forma a se interpretarem todos os dados iniciais, realizando a pré-análise. Em seguida, os dados foram explorados com mais cuidado na tentativa de categorizar cada uma das respostas. Encontraram-se 3 categorias que identificam as unidades de análises para cada questão aplicada. Sendo elas: satisfatória, regular ou insatisfatória. Essa classificação se deu conforme as respostas esperadas pelo professor.

\section{QUESTIONÁRIO INICIAL}

No Quadro 3, são apresentados alguns exemplos das respostas dos alunos, bem como a categorização, por fim, o tratamento dos dados.

Quadro 3 - Exemplos de respostas a pergunta sobre misturas homogêneas

\begin{tabular}{c|c|c}
\hline Categorias & Exemplos de respostas & $\begin{array}{c}\text { Número de } \\
\text { respostas }\end{array}$ \\
\hline Satisfatória & $\begin{array}{c}\text { É uma mistura lisa, massa de bolo, etc. } \\
\text { Regular }\end{array}$ & $\begin{array}{c}\text { Mistura homogênea é quando ela se mistura com uma } \\
\text { outra coisa. }\end{array}$ \\
\hline Insatisfatória & $\begin{array}{c}\text { São misturas que uma é compatível com a outra, ex. leite } \\
\text { com chocolate, água e café. }\end{array}$ & 22 \\
\hline & $\begin{array}{c}\text { Homó quanea é uma mistura (Ex.: Água, óleo e gelo). } \\
\text { São misturas que não se fundem. }\end{array}$ & 8 \\
\hline
\end{tabular}

Fonte: Autoria própria (2017). 
Segundo Antunes (2013, p.47), um sistema homogêneo "apresenta aspecto uniforme e as mesmas características em toda a sua extensão. Esse sistema é monofásico". Dessa forma, considerando as respostas acima relacionadas, 73\% dos alunos responderam de maneira regular e grande parte delas deram exemplos ligados com o cotidiano, os demais apresentaram respostas insatisfatórias e nenhuma resposta foi categorizada como satisfatória por erros conceituais evidentes e já esperados.

Antunes (2013, p.47) define um sistema heterogêneo como aquele que "apresenta aspectos e características diferentes em sua extensão. Esse sistema pode ser formado por duas ou mais fases". Dessa forma, as respostas dos alunos foram categorizadas de acordo com o Quadro 4. As respostas mostram que na segunda questão, sobre misturas heterogêneas, $60 \%$ dos alunos responderam regularmente com alguns aspectos próximos a definição mais adequada, os outros $40 \%$ responderam insatisfatoriamente.

\begin{tabular}{c|c|c}
\multicolumn{2}{c}{ Quadro 4-Exemplos de respostas a pergunta sobre misturas heterogêneas } \\
\hline Categorias & Exemplos de respostas & $\begin{array}{c}\text { Número de } \\
\text { respostas }\end{array}$ \\
\hline Satisfatória & $\begin{array}{c}\text { Misturas que não se fundem, ex. óleo e água. } \\
\text { Heterogênea é várias misturas. }\end{array}$ & 18 \\
\hline Regular & $\begin{array}{c}\text { É uma mistura de várias coisas que não ficam juntas. } \\
\text { Insatisfatória }\end{array}$ & $\begin{array}{c}\text { São misturas que causam reações químicas, ex. óleo e } \\
\text { fogo. }\end{array}$ \\
\hline & $\begin{array}{c}\text { É quando envolve mais de uma substância. } \\
\text { Misturas de várias substâncias diferentes. }\end{array}$ & 12 \\
\hline
\end{tabular}

Fonte: Autoria própria (2017).

As respostas dadas pelos alunos para misturas homogêneas e heterogêneas apresentaram comportamento parecido, justifica-se o grande número de respostas regulares por já terem visto os conceitos em sala, entretanto, não sabiam justificar com exatidão, utilizando linguagem adequada para definição.

Um exemplo desta dificuldade em explicar os conceitos com uma linguagem clara é a definição de mistura heterogênea apresentado por um dos alunos como: Misturas de várias substâncias diferentes. Não podemos inferir a real intenção do aluno ao descrever a mistura heterogênea dessa maneira, mas acreditamos que o termo substâncias possa ser substituído por fases, se assim fosse, poderíamos considerar a resposta como satisfatória. Entretanto, o uso inadequado da linguagem fez com que a resposta fosse considerada insatisfatória.

A terceira questão foi elaborada de forma aberta, solicitando que os alunos escrevessem tudo que sabiam sobre densidade, entretanto, $90 \%$ dos alunos afirmaram não saber responder ou não se lembravam do conceito e dessa forma deixaram em branco, apenas $3(10 \%)$ dos alunos responderam e as respostas foram insatisfatórias, como exemplo: Atmosfera massa muito densa, pesada.

A quarta questão foi elaborada na tentativa de tentar estabelecer relação entre densidade e mistura. Novamente, apenas três alunos responderam e também de forma insatisfatória. As respostas mostram a dificuldade dos alunos sobre conceitos de misturas e densidade. 


\section{PRIMEIRO MOMENTO}

Neste momento notou-se que, com as perguntas a turma ficou motivada, os alunos começaram a sugerir hipóteses e questionamentos que eram respondidos entre eles. Alguns pontos foram levantados por eles no momento:

- A densidade influencia, caso contrário, não haveria essa informação.

- O mais pesado deve ficar por baixo.

Esses pontos instigados pelos alunos é o que Delizoicov, Angotti e Pernambuco (2002, apud MARENGÃO, 2012, p. 29), denominam de "concepções alternativas" ou "conceitos intuitivos". Estes autores também relatam que a problematização pode levar os alunos a necessitarem de novos conhecimentos para enfim chegar a uma conclusão da problematização inicial.

O que foi verificado ao término deste primeiro momento, pois, mesmo com todas as respostas e questionamentos e com os conceitos intuitivos que cada aluno leva consigo, apenas uma hipótese foi comprovada como correta, como apresentado na Figura 2.

Figura 2 - Hipótese correta

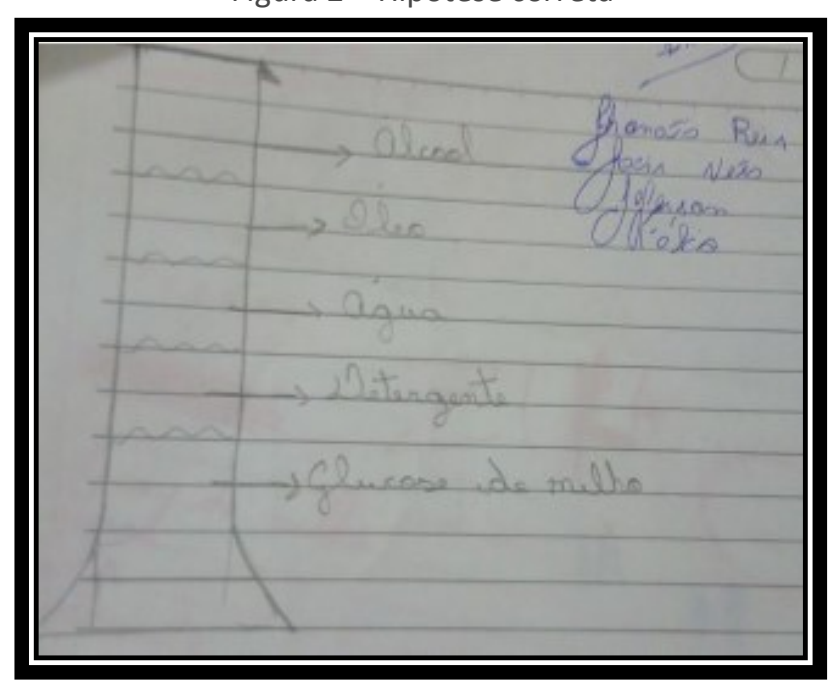

Fonte: Autoria própria (2017).

\section{SEGUNDO MOMENTO}

Cada grupo formulou incialmente a sua hipótese e neste momento eles realizaram a atividade experimental, tal como estava no papel.

O primeiro grupo havia formulado uma hipótese onde a glucose de milho deveria ser o último elemento a ser colocado, ficando no topo da torre, quando indagados o porquê dessa hipótese, um dos integrantes respondeu que seria porque a glucose é mais pastosa e daria mais estabilidade ficando por cima.

Os próprios alunos refutaram a hipótese, afirmando que: a glucose é mais pesada, então ela vai afundar, ou ainda, está errado porque a glucose vai se misturar com os outros quando for colocada. 
Nesse momento, o professor ficou responsável por estabelecer os conceitos corretamente, como a diferença entre peso e densidade; a diferença entre mistura homogênea e mistura heterogênea, de forma que eles compreendessem que a expressão - eles vão se misturar - estava sendo utilizada de maneira errada.

O segundo grupo havia formulado a hipótese colocando o óleo primeiro, logo em seguida a água e depois o detergente. Questionados o porquê da escolha, eles responderam que o óleo é difícil de tirar da mão, só com água não é possível, com o detergente fica mais fácil, seguiram essa lógica como premissa para a elaboração da hipótese.

Essa hipótese despertou a curiosidade dos alunos que refutaram dizendo que era outro fenômeno envolvido e não apenas o de misturas e densidade. Ao professor coube estabelecer as relações corretas e a explicação de que se tratava da solubilidade dos elementos envolvidos, conceito trabalhado nas próximas aulas.

As hipóteses 3 e 4 foram elaboradas da mesma forma, seguindo-se a sequência contrária a correta, ou seja, álcool, óleo, água, detergente e glucose de milho, ambos responderam que não havia nenhum motivo especial para formulação dessas hipóteses, apenas imaginaram que seria assim.

Apenas o quinto e último grupo formulou a hipótese correta, conforme apresentado na Figura 2. As hipóteses executadas pelos alunos são apresentadas na Figura 3.

Figura 3 - Execução das hipóteses formuladas

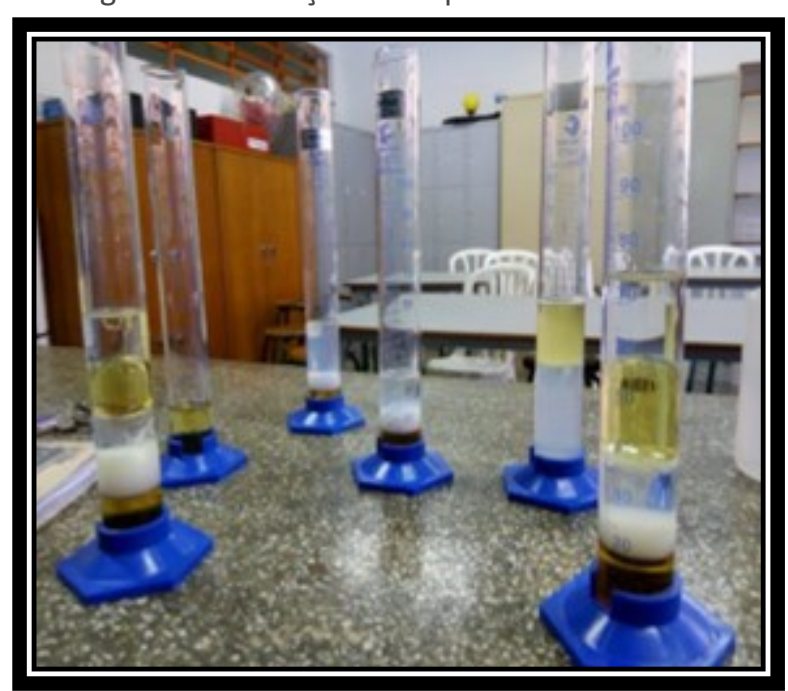

Fonte: Autoria Própria (2017).

\section{TERCEIRO MOMENTO}

Notou-se o maior envolvimento e interesse dos alunos pela atividade prática, buscando-se hipóteses e questionamentos para a execução da proposta da aula.

A evolução dos conhecimentos sobre os conteúdos específicos de Química e o os porquês gerados durante o terceiro momento, foram todos resultados no questionário final. 


\section{QUESTIONÁRIO FINAL}

A fim de verificar se houve alteração nas concepções dos alunos sobre conteúdos de densidade, mistura homogênea e heterogênea e analisou-se que para as questões 1 e 2 sobre misturas homogêneas e heterogêneas os alunos apresentaram um conhecimento científico satisfatório, sendo que $100 \%$ dos alunos expuseram as definições de forma correta.

Para a terceira questão sobre densidade, $70 \%$ dos alunos responderam de forma satisfatória, outros $13 \%$ responderam de forma regular e $17 \%$ não souberam responder.

Para a quarta questão que buscava estabelecer a relação entre misturas e densidade, todos os alunos responderam, mostrando uma grande evolução, algumas respostas são expostas a seguir:

As misturas podem ser homogêneas ou heterogêneas, sendo que a densidade de uma mistura é relacionada com a densidade de seus componentes.

A densidade é específica de cada substância e determina se vai haver mistura ou não.

A inserção da atividade prática investigativa nas aulas de Química mostrou-se uma estratégia eficiente no processo de aprendizagem dos alunos, percebe-se isso por meio das respostas dos questionários aplicados no início e ao final da atividade. A evolução dos alunos foi significativa, principalmente em relação a linguagem científica, observando-se respostas mais elaboradas, visto que inicialmente foi possível notar uma dificuldade grande dos alunos em compreender os conceitos específicos.

Ressalta-se ainda, as falas da professora regente da turma que no início da atividade informou que a turma tinha um aproveitamento mínimo na disciplina e o pouco que acrescentar-lhes a aprendizagem seria valioso. Ainda, ao final da atividade destacou que esse momento foi muito importante para os alunos, devido ao fato de ter sido o primeiro contato deles com a atividade prática.

\section{CONCLUSÃO}

O Estágio Supervisionado é o momento em que o licenciando adquire autonomia para portar-se como professor, oportunizando a aplicação de seus conhecimentos acadêmicos em situações da prática profissional e criando a possibilidade do exercício das suas habilidades.

A elaboração do projeto desenvolvido no Estágio Supervisionado da UTFPRLondrina colocou a prática de pesquisa à disposição do licenciando. Essa prática oportunizou ao estudante investigar de forma adequada a realidade escolar, sendo uma estratégia importante para despertar o interesse ao desenvolvimento de atitudes de pesquisador. As competências de pesquisa, assim desenvolvidas, são cruciais para a construção dos saberes docentes, formando professores práticos reflexivos.

Pode-se concluir que o trabalho foi de grande relevância para o sua capacidade de planejar propostas metodológicas para o ensino de Química. 
Dessa forma, essa atividade permitiu a incorporação de atitudes práticas e uma visão crítica da sua área de atuação profissional.

Identificou-se com a atividade desenvolvida a evolução dos alunos, entretanto ainda observam-se grandes dificuldades na assimilação dos conceitos. Tais dificuldades podem estar relacionadas a falta de estímulo para a aprendizagem que poderia ser desenvolvido por meio de propostas pedagógicas como a intervenção realizada. Outro fator importante é a falta de apoio ao professor, os materiais utilizados na prática foram comprados pelo próprio aluno-estagiário, não havendo o apoio necessário para a execução da atividade.

Diante desta perspectiva, percebeu-se a necessidade de fornecer apoio aos professores para a realização de atividades de caráter investigativo, proporcionando materiais e preparo adequados para condução desta metodologia. Com esta pesquisa, pretende-se que os professores consigam ir além dos experimentos demonstrativos, observados ainda como única opção nas aulas de Química. 


\title{
Investigative experimentation in chemistry teaching: building a liquid tower
}

\begin{abstract}
There is an extensive body of literature that points out the reasons for students' difficulties in assimilating concepts, the presentation of concepts makes them abstract and unrelated to reality which can cause disinterest in learning. Thus, this research has as objective the application of strategies that are able to overcome this disinterest. Stimulating the students to become involved with the activity and creating hypotheses and questions about the studied phenomena. For that, we use the investigative practice and the activity was carried out in a first-year high school class based on the methodology proposed by Delizoicov, Angotti, and Pernambuco (2002), called "three pedagogical moments", the three steps are problematization, the organization of knowledge and application of knowledge. With the "three pedagogical moments", It is possible to verify the difficulties of the students in the first moment and to stimulate them to evolve in the second and third moment, proving the importance of this approach in the teaching of chemistry. It is important to emphasize that the teacher should be encouraged and prepared so that the actions are effective in the process of teaching and learning.
\end{abstract}

KEYWORDS: Chemistry teaching. Experimental Activity. Investigative Approach. 


\section{AGRADECIMENTOS}

À fundação CAPES, à Universidade Tecnológica Federal do Paraná (UTFPR) e às Universidades Estaduais de Londrina (UEL) e de Maringá (UEM).

\section{REFERÊNCIAS}

ANTUNES, M. T. Ser Protagonista - Química. 2. ed., 2 v, São Paulo: Edições SM, 2013.

ARAÚJO, M. S. T.; ABIB, M. L. V. S. Atividades experimentais no ensino de física: diferentes enfoques, diferentes finalidades. Revista Brasileira de Ensino de Física, Porto Alegre, v.25, n.2, p. 176-194, 2003.

BARDIN, L. Análise de conteúdo. 70. ed. Lisboa, 2007.

BARATIERI, S. M.; BASSO, N. R. S.; BORGES, R. M. R.; ROCHA FILHO, J. B. Opinião dos estudantes sobre a experimentação em química no Ensino médio.

Experiências em Ensino de Ciências, v. 3, n. 3, p. 19-31, 2008. Disponível em: <http://if.ufmt.br/eenci/?go=artigos\&idEdicao=20> Acesso em: 2 abr. 2017.

DELIZOICOV, D.; ANGOTTI, J. A. P. Metodologia do ensino de Ciências. 6. ed. São Paulo: Cortez, 2000.

DELIZOICOV, D.; ANGOTTI, J. A. P.; PERNAMBUCO, M. M. Ensino de Ciências: Fundamentos e Métodos. São Paulo: Cortez, 2002.

GABEL, D. L.; SHERWOOD, R. D. e ENOCHS, L. Problem-solving skills of high school chemistry student. J. Res. Sci. Teach, v. 21, p. 221-233, 1984. Disponível em: <http://onlinelibrary.wiley.com/doi/10.1002/tea.3660210212/full> Acesso em: 2 abr. 2017

GIL-PÉREZ, D.; VALDÉS CASTRO, P. La orientación de las prácticas de laboratorio como investigación: un ejemplo ilustrativo. Enseñanza de las Ciencias, v. 14, n. 2, p. 155-163, 1996. Disponível em:

<http://www.raco.cat/index.php/Ensenanza/article/view/21444> Acesso em: 1 abr. 2017

GIORDAN, M. O papel da Experimentação no ensino de ciências. Química Nova na Escola, n. 10, p. 43-49, 1999. Disponível em:

<qnesc.sbq.org.br/online/qnesc10/pesquisa.pdf> Acesso em: 1 abr. 2017 
GONZALES, E.M. Que Hay de Renovar en Los Trabajos Prácticos? Ensenãnza de Las Ciências, v. 10 n.2, p. 206-211, 1992. Disponível em:

<www.raco.cat/index.php/Ensenanza/article/download/.../93190> Acesso em: 2 abr. 2017

HODSON, D. Experiments in science and science teaching. Educational Philosophy and Theory, v. 20, n. 2, p. 53-66, 1988.

LÜDKE, M.; ANDRÉ, M. E. D. A. Pesquisa em educação: abordagens qualitativas. São Paulo: EPU, 1986.

MALDANER, O. A. A formação inicial e continuada de professores de Química. Ijuí: Unijuí, 2003.

MARENGÃO, L. S. L. Os Três Momentos Pedagógicos e a elaboração de problemas de Física pelos estudantes. 2012. 82f. Dissertação (Mestrado em Educação em Ciências e Matemática) - Universidade Federal de Goiás, Goiânia, 2012.

NUNES, A. S.; ADORNI, D. S. O ensino de química nas escolas da rede pública de ensino fundamental e médio do município de Itapetinga-BA: $O$ olhar dos alunos. In: Encontro Dialógico Transdisciplinar - Enditrans, 2010, Vitória da Conquista, BA. - Educação e conhecimento científico, 2010.

OLIVEIRA, N. de; SOARES, M. H. F. B. As atividades de experimentação investigativa em ciência na sala de aula de escolas de ensino médio e suas interações com o lúdico. In: ENEQ, 15, 2010. Brasília. Resumos... Brasília: UnB, 2010. 12.

SANTOS, W. L. P.; SCHNETZLER, R. P. Função Social: o que significa ensino de química para formar cidadão? Química Nova na Escola, n.4, nov. 1996.

Disponível em: <qnesc.sbq.org.br/online/qnesc04/pesquisa.pdf> Acesso em: 2 abr. 2017.

SCHNETZLER, R. P.; ARAGÃO, R. M. R. Importância, Sentido e Contribuições de Pesquisas para o Ensino de Química. Química Nova na Escola. n.1, p. 27-31, 1995. Disponível em: <qnesc.sbq.org.br/online/qnesc01/pesquisa.pdf > Acesso em: 1 abr. 2017.

PARANÁ. Secretaria de Estado da Educação - SEED. Diretrizes curriculares de Química para a Educação Básica. Curitiba - PR, 2006. 
SUART, R. C.; MARCONDES, M. E. Atividades Experimentais Investigativas: habilidades manifestadas por alunos do Ensino Médio. In: XIV Encontro Nacional de Ensino de Química. Atas... Universidade Federal do Paraná, 2008.

ZÔMPERO, A. F.; LABURÚ, C. E. Atividades investigativas no Ensino de Ciências: Aspectos históricos e diferentes abordagens. Revista Ensaio, n.3, p. 67-80, 2011. Disponível em: <http://www.scielo.br/pdf/epec/v13n3/1983-2117-epec-13-0300067.pdf> Acesso em: 1 abr. 2017.

WILSEK, M. A. G. Ensinar e Aprender Ciências no Ensino Fundamental com Atividades Investigativas através da Resolução de Problemas. Curitiba, 2009. Disponível em: <http://www.diaadiaeducacao.pr.gov.br/portals/pde/arquivos/1686-8.pdf>. Acesso em: 02 abr. 2017.

Recebido: 30 jul. 2017

Aprovado: 10 jan. 2018

DOI: $10.3895 /$ actio.v3n1.6835

Como citar:

BALDAQUIM, M. J.; PROENÇA, A. M.; SANTOS, M. C. G. FIGUEIREDO, M. C.; SILVEIRA, M. P. A

experimentação investigativa no ensino de química: construindo uma torre de líquidos. ACTIO, Curitiba, v. 3,

n. 1, p. 19-36, jan./abr. 2018. Disponível em: <https://periodicos.utfpr.edu.br/actio>. Acesso em: XXX

Correspondência:

Matheus Junior Baldaquim

Universidade Estadual de Maringá, Avenida Colombo, 5790, bloco F67, sala 007, CEP: 87020-900, Maringá,

Paraná, Brasil.

Direito autoral: Este artigo está licenciado sob os termos da Licença Creative Commons-Atribuição 4.0

Internacional.

(c) (1) 